\title{
ROBERT HOWARD
}

\section{The Postgraduate Medical Education and Training Board and quality assurance of training standards}

The Postgraduate Medical Education and Training Board (PMETB) is an independent statutory body which has been responsible since 30 September 2005 for establishing and securing standards of post-foundation years medical education and training in the UK. The statutory objectives of PMETB include the safeguarding of service users and ensuring that the needs of both trainees and their employers are met. The PMETB has set a number of generic training standards and, in consultation with each of the relevant Colleges, a detailed curriculum for each specialty has been developed. Its quality assurance programme differs in some important ways from the traditional College-led and visit-based system, with greater reliance on the postgraduate deans' quality management systems. The quality assurance process of PMETB aims to ensure that the training standards are met within each deanery, so that training programmes can continue to receive approval.

\section{Generic training standards}

Generic standards have been set by PMETB and these must be met for training to receive approval in all specialties, including general practice. A series of nine domains within which standards can be set and assessed has emerged and has become a pivotal component of the quality assurance process. It is important that those involved in the delivery of specialist training are aware of these domains. Mandatory and developmental standards within each of the nine domains are described in detail in Generic Standards for Training (PMETB, 2006), but a brief summary of each is given below.

\section{Domain 1}

Patient safety: the duties, working hours and supervision of trainees must be consistent with the delivery of highquality safe patient care. Trainees must be appropriately supervised by clearly identified, competent and accessible trainers and the terms and conditions of their posts must be consistent with the delivery of high-quality safe patient care. Within psychiatry, the safety of trainees and other staff members has always been an area of particular interest in the assessment of training, and it seems reasonable to assume that this can continue to be monitored within this domain.

\section{Domain 2}

Quality assurance, review and evaluation: the quality control of postgraduate training must be carried out locally by deaneries, working with others as appropriate but within an overall delivery system for postgraduate medical education for which deans are responsible. Deaneries must have processes for local quality control of all postgraduate posts and programmes to ensure that the requirements of PMETB's standards for training, assessment and curricula are met.

\section{Domain 3}

Equality, diversity and opportunity: postgraduate training must be fair and based on principles of equality. Training programmes must comply with employment law and all equal opportunity legislation, and deaneries must take all reasonable steps to ensure that programmes can accommodate trainees with individual requirements to work flexibly.

\section{Domain 4}

Recruitment, selection and appointment: processes for recruitment, selection and appointment must be open, fair and effective. Selection panels must consist of individuals who have been trained in selection principles and processes. Panels must select candidates on the basis of open competition and use criteria and processes which treat eligible candidates fairly.

\section{Domain 5}

Delivery of curriculum, including assessment: the requirements set out in the curriculum must be delivered. The requirements of the curricula set by the College and approved by PMETB are being met at the local level. Each post should enable the trainee to acquire appropriate 
an

editorial competence. Trainees must be able to access training days, courses and other material constituting a training programme. The curriculum should include a system for assessment of trainees, who should receive feedback on their performance and training progress within each post.

\section{Domain 6}

Support and development of trainees, trainers and local faculty: trainees must be supported to acquire the necessary skills and experience through induction, effective educational supervision, an appropriate workload, personal support and time to learn. All trainees must attend a departmental induction at the beginning of each post or programme to ensure that they understand the curriculum, how their post fits within the programme and their duties and reporting arrangements. A meeting should take place with the identified educational supervisor at the commencement of every post, with discussion of the educational framework of the post and the setting of training aims and objectives. Trainees must meet with their educational supervisor at least every 3 months to discuss progress and how outstanding training needs will be met. In their posts, trainees must be enabled to learn new skills under supervision and should be exposed to working patterns and intensity of work appropriate for learning. Educational supervisors must have been trained and selected for this role. Resources and time must be available for trainers to carry out thei duties and should be indicated in their job and personal development plans.

\section{Domain 7}

Management of education and training: education and training must be planned and maintained through transparent processes which show who is responsible at each stage. Training programmes must be supported by management plans containing a schedule of responsibilities and accountabilities of the Postgraduate Dean, members of the local faculty, individual trainers, trainees, employing trusts and commissioners of health services and educational programmes.

\section{Domain 8}

Educational resources and capacity: the educational facilities, infrastructure and leadership must be adequate to deliver the curriculum. There must be a suitable ratio of trainers to trainees and access to educational facilities (library, meeting rooms), as well as educational resources (e.g. the internet, audio-visual aids).

\section{Domain 9}

Outcomes: the impact of the standards must be tracked against trainee outcomes and clear linkages should be reflected in developing standards. The content and scope of this domain is still the subject of discussion and consultation. The current developmental standard recommends that trainees should have access to outcomes of assessments, record of in-training assessments (RITAs) and exam pass rates for each programme and location, benchmarked against other programmes.

\section{How PMETB will determine whether standards are met}

The PMETB has already begun to collect evidence directly from trainees by large-scale survey. Data collected routinely by deaneries as part of their quality control processes will also be used, together with evidence from logbooks, examination success rates, RITA form returns and career progression from individual programmes. Finally, PMETB will carry out visits to deaneries and training providers. Visits will be part of a regular inspection process or can be triggered at any time by evidence of failure to meet standards or poor practice.

\section{PMETB visits}

Deanery-wide cross-specialty visits are different from the College's system of visits that trainers have become familiar with in recent years. The focus of the PMETB visiting process is now the deanery, and the intention is that the process should be 'high-level light touch'. Visiting teams will contain consultants both from the specialties to be examined and from other specialties, a representative from another postgraduate deanery, a general practitioner and lay visitors. The team will interview the Postgraduate Dean, relevant programme directors and a representative sample of trainees and trainers at individual training sites within the deanery. At the end of the visit, the team will produce a visit report which will detail whether and how standards are being met, and will highlight both areas of good practice and those where improvement is needed. The report will also include recommendations made to the deanery, to the specialties visited and to PMETB itself, as a result of the visit. The deanery will respond in full to the report and both the deanery's response and the report will be considered by PMETB when making its final and binding decision on approval. The final approval document will be made publicly available on the PMETB website (http:// www. pmetb.org), supported by the original report.

\section{Personal experience of a PMETB visit}

Along with many of the College's recent convenors, I watched the demise of the established system for visiting training schemes in 2005/6 with some dismay. It was not clear to me - or anyone I spoke to - how exactly PMETB were going to fill the 'quality assurance gap' that the College had hitherto filled. My experience of visiting and feeding back reports on individual senior house officer training schemes to local postgraduate deans was that they would often have been previously unaware of the difficulties that had emerged and were dependent on 
the College visits for concrete information about how local training schemes were performing. I have now been on a deanery-wide PMETB visit and found this reassuring in some respects. Within the selected training sites where we were able to interview trainees and trainers and visit the facilities where training took place, the process felt as robust and searching as the 'old' College visits. The visit made me question whether postgraduate deaneries truly have the capacity to effectively carry out quality assurance of training programmes in all specialties. Hopefully, the College will be able to continue to play a part in helping the postgraduate deans to meet the PMETB standards for specialist training in psychiatry. In the meantime, PMETB is always interested to hear from psychiatrists who are able to help by participating in visits.

\section{Declaration of interest}

None.

editorial

\section{Acknowledgement}

Thanks to Gabrielle Shaw, Head of Approvals and Visits at PMETB for comments on a draft of this paper.

\section{Reference}

POSTGRADUATEMEDICAL EDUCATION www.pmetb.org.uk/media/pdf/h/s/ AND TRAINING BOARD (2006) Generic GenericStandardsForirainingFinal05 Standards for Training. http:// April06_1.pdf

Robert Howard Professor of Old Age Psychiatry and Psychopathology, MRC Centre for Neurodegeneration Research, Institute of Psychiatry, DeCrespigny Park, Camberwell, London SE5 8AF, email: r.howard@iop.kcl.ac.uk 